\title{
Estado e democracia no discurso oficial do Estado Novo
}

Tiago Losso*

\section{Introdução'}

uando estava às voltas com o projeto da Constituição que estava sendo elaborada por Francisco Campos, Vargas anotou em seu diário um fato revelador a respeito dos rumos que a política brasileira tomaria nos próximos anos. O jornal Correio da Manhã havia publicado uma nota informando de uma missão do Deputado Federal Negrão de Lima ao Norte do país. Esse vazamento obrigou o Presidente da República a desdobrar-se para desmentir a existência de um plano golpista. Alarmado com a situação, Vargas exclama: "Como a censura deixara publicar? Quem [fora] o responsável pela nota e pela publicação? Tomavam-se providências a respeito sem resultado!"2 (cf. VARGAS, 1995, p. 81). No mesmo dia, a Chefatura de Polícia do Distrito Federal foi encarregada de censurar a imprensa, as agências telegráficas e as rádios, atribuição anteriormente do Ministério da Justiça (idem, p. 81, nota 47). Dias depois, o Brasil assistiria ao aparecimento do Estado Novo.

Tiago Losso é Doutor em Ciências Sociais pela Universidade Estadual de Campinas (Unicamp), pesquisador do Núcleo de Estudos sobre Pensamento Político (NEPP) da Universidade Federal de Santa Catarina (UFSC) e Professor Substituto no Departamento de Sociologia e Política da UFSC. Endereço eletrônico: tiagolosso@gmail.com.

1 Este artigo é uma versão resumida do segundo capítulo da tese de Doutorado defendida pelo autor no Programa de Doutorado em Ciências Sociais da Universidade Estadual de Campinas (Unicamp), sob orientação de Elide Rugai Bastos.

2 Nota do dia 5 de novembro de 1937. 
No dia 10 de novembro de 1937, uma nova ordem começa a ser montada. As duas casas do Congresso Nacional amanhecem cercadas pela polícia e, no Palácio Guanabara, o Ministério reuniuse para assinar a nova Constituição, elaborada pelo novo Ministro da Justiça, Francisco Campos. Finalmente, às oito horas da noite, Vargas pronuncia no rádio seu Manifesto à nação, em que decreta a nova Constituição e outras medidas institucionais que iriam "reajustar o organismo político às necessidades econômicas do país". Esse reajuste diz respeito à organização do país, ao molde de suas instituições e à maneira como o país reconhecer-se-ia. Além da inflexão da política institucional, as idéias políticas brasileiras também passariam por uma reacomodação: estariam, daquele momento em diante, encarregadas de ajustar o organismo político ao Brasil real.

Neste artigo, pretendo analisar dois dos movimentos de acomodação dessas idéias políticas, investigando traços do discurso oficial do Estado Novo, especificamente aquele que compõe as páginas de Cultura Política, revista editada e publicada pelo Departamento de Imprensa e Propaganda (DIP) entre 1941 e 1945. Do vasto manancial de temas que poderiam ser estudados, isolarei duas idéias que, acredito, são simultaneamente centrais e exemplares: democracia e Estado. Essas duas idéias estão presentes em grande parte da produção discursiva oficial do Estado Novo, como um pretenso esforço de alinhar as instituições políticas do país à sua realidade social.

A procura do verdadeiro Brasil não era uma preocupação exclusiva dos que assinaram o novo corpo legal brasileiro em 1937. O pensamento social brasileiro produziu impressões, noções e visões sobre esse assunto, chegando, por vezes, a propor ações efetivas para corrigir pretensos erros. Ao longo desse processo, foi constituído um vocabulário que, depois de depurado, passou a ser usado com mais regularidade após a emergência do Estado Novo. Nas páginas de Cultura Política, esse vocabulário será largamente mobilizado, com o intuito de legitimar e investigar as novas conformações das instituições políticas brasileiras, já sob a ditadura inaugurada em 1937. 


\section{Cultura Política: uma apresentação}

Se o Estado Novo foi capaz de elaborar um discurso, este foi impresso na revista Cultura Política. Apontada como principal veículo de expressão das idéias oficiais do Estado Novo (cf. GOMES, 1982), a revista contou com a colaboração de nomes importantes da intelectualidade brasileira dos anos 1930 e $1940^{3}$. Almir de Andrade, diretor da revista, relata ter sido um convite de Lourival Fontes o primeiro passo para a elaboração do periódico. A idéia de Fontes teria sido a publicação de uma revista de cultura no âmbito do regime inaugurado em 1937: "Planejei a Revista de uma forma que pudesse interessar ao público pela variedade de assuntos, pelo nível intelectual, e pudesse também reunir toda aquela intelectualidade que girava em volta do governo, alguns até opositores do governo, mas que, para fazer uma revista de cultura, colaboraram"4 (ANDRADE, 1985, p. 1).

Mas cultura não seria o único assunto veiculado em Cultura Política. Seguindo as indicações de Mônica Pimenta Velloso, podemos apontar os principais temas do discurso desse periódico: "[...] A recuperação do passado; a nova concepção de política, cujos desdobramentos são a "cultura política"; o novo homem, particularmente o intelectual; o mito Vargas; e finalmente a relação consenso e força do novo regime" (Velloso apud GOMES, 1982).

Estruturada com base nesses temas, Cultura Política terá como objetivo mapear o pensamento brasileiro do período, tendo sempre como norte organizativo a relação desse pensamento com as idéias que animam o regime surgido em 1937.

3 Por exemplo: Graciliano Ramos, Gilberto Freyre, Oliveira Vianna ou, ainda, Azevedo Amaral. Informações detalhadas podem ser obtidas em Gomes (1982).

4 E não foi difícil encontrar autores dispostos a colaborar no periódico. Andrade (1986a, p. 3) completa: "Pode-se dizer que só batalhei para conseguir colaboração para lançar a revista. O primeiro número, segundo e terceiro. Daí por diante, nunca mais tive que pedir. Eles vinham a mim. O pessoal todo vinha, inclusive porque a revista na época pagava de colaboração um preço que ninguém pagava. Pagávamos um preço relativamente alto. Até em alguns casos o dobro do que os jornais e revistas pagavam. De forma que havia uma grande afluência de ofertas de trabalho. E o trabalho que passei a ter desde o segundo ou terceiro número foi selecionar o que me ofereciam". 
Fundada e dirigida por Almir de Andrade, a revista teve seu primeiro número lançado em março de 1941. Já nesse número, Andrade deixa clara a intenção de relacionar o pensamento brasileiro com o regime de 1937:

As páginas desta Revista procurarão definir e esclarecer esse rumo [tomado em novembro de 1937]. Eles serão, nesse sentido, um espelho do Brasil. O que somos, o que pensamos, o que realizamos em todos os setores da nossa atividade criadora - na política, na economia, na técnica, nas artes, nas letras, nas ciências - ficará estampado nestas páginas, através do depoimento de todas as gerações que hoje vivem, em todas as cidades e rincões do Brasil. [...] Eles [os depoimentos] falarão do Brasil. Porque eles são o Brasil (ANDRADE, 1941a, p. 8).

Um misto de discursos, doutrinas, depoimentos, relatos e relatórios irá desenhar o retrato de um "novo" Brasil. E esse Brasil era um país marcado definitivamente pelo regime de Vargas. Pelo Estado Novo:

Mas na Cultura Política nós tínhamos a preocupação de fazer uma coisa mais ou menos imparcial, quer dizer, se fazíamos propaganda do governo, fazíamos conscientemente, sabendo... Convictamente. De forma que com todo o aspecto de uma coisa sincera, e todos os que escreviam na Cultura Política tinham este espírito de dizer o que sentiam realmente. Por isso é que escreviam intelectuais de todas as carreiras, de todas as camadas (ANDRADE, 1986a, p. 9; grifos no original).

O Estado Novo ocuparia posição central nas páginas de Cultura Política. Devidamente encaminhadas, as idéias que compunham o periódico confluíam para a mesma impressão: as vantagens do regime. Almir de Andrade não credita tal fato à vontade deliberada dos que controlavam a revista, ou mesmo a algum tipo de ingerência do DIP, mas, sim, ao correto e natural desenrolar das argumentações: "Sem a preocupação de fazer propaganda disso ou daquilo. Mas calhava que as conclusões muitas vezes vinham justificar os atos do governo. Isso é que é mais importante do que uma propaganda aberta e direta. De modo que essa foi a orientação que dei e que se manteve durante os cinco anos e com resultados muito bons [...]" (idem, p. 9-10). 
Um cuidado especial, portanto, com o louvor ao novo regime. Cuidadoso ao apontar as vantagens da ordem inaugurada em 1937. Se atentarmos para o público-alvo da revista, "uma elite", nas palavras de seu diretor, é razoável supor que esse cuidado seja realmente um dado relevante para a compreensão das características do periódico (idem, p. 6-10).

Para viabilizar essa empreitada política e intelectual, a revista contará com as já citadas colaborações, que serão distribuídas em seções específicas. Uma breve descrição dessas subdivisões de Cultura Política indica a amplitude do projeto iniciado por Almir de Andrade em 1941.

A seção "Problemas políticos e sociais" abre Cultura Política, com uma descrição feita pelo editor nos seguintes termos: "É consagrada esta seção ao estudo de todos os problemas políticos e sociais do Brasil - quer os problemas de ordem geral, doutrinária, histórica, econômica, administrativa, educacional, sanitária, militar, operária, quer os problemas regionais ou específicos de cada zona territorial e de cada paisagem humana"5.

Em seguida, resume-se o objetivo da seção "O pensamento político do Chefe de Governo":

Nestes dez anos de lutas políticas pela estabilização das conquistas e concretização das aspirações revolucionárias de 1930, tem sido o Presidente Getúlio Vargas o pensamento diretor e inspirador da nossa vida pública $[. .$.$] .$

[...]

Definir e interpretar esse pensamento - esclarecê-lo sob todos os aspectos - significa, conseguintemente, um esclarecimento e uma interpretação dos próprios rumos políticos brasileiros, que nele se têm espelhado em seus momentos mais significativos.

"A estrutura jurídico-política do Brasil" fecha o grupo de intervenções que podemos chamar de "políticas", expondo sua proposta da seguinte forma:

5 A abertura de cada seção de todos os números de Cultura Política trazia sempre uma breve apresentação. 
A Constituição de 10 de novembro de 1937 se caracteriza por dois traços fundamentais: seu sadio realismo, adaptado às realidades e tradições brasileiras; seu espírito avançado e integrado nas grandes correntes da evolução política do mundo moderno.

Para esclarecer esses dois traços e acompanhá-los em seus desenvolvimentos e em suas raízes profundas, Cultura Política vai promover, nessa seção, amplos debates e comentários em torno dos artigos da nossa carta constitucional, confiados sempre a magistrados, membros do Ministério Público, Desembargadores e Ministros do Supremo Tribunal, Jurisconsultos ou figuras eminentes das letras jurídicas do país.

Iniciando um conjunto de temas menos candentes, o periódico revela a preocupação em diversificar sua área de intervenção intelectual. Assim, "Textos e documentos históricos” apresenta a seguinte proposta: "Quaisquer citações bibliográficas de velhos autores ou de novos, anteriores a 1930, e quaisquer documentos históricos que interessem à vida política do Brasil terão acolhida nesta seção".

"A atividade governamental" pretendia trazer notícias mensais das realizações do Estado Novo. "Brasil social, intelectual e artístico", por sua vez, iria mostrar a nova realidade nacional, marcada por novas formas de ordenamento social, oriundas das práticas e estímulos do novo regime:

A ordem social, a paz, o trabalho, a tolerância política favorecem o desenvolvimento de todas as capacidades criadoras da coletividade $[\ldots]$.

$[\ldots]$

O Brasil social, intelectual e artístico há de espelhar-se aqui, no seu surpreendente espetáculo de renascimento, testemunhando, como um depoimento vivo e irretorquível, os benefícios de paz, de concórdia, de tolerância e de unidade, que hoje desfrutamos.

Por fim, "Política militar e defesa nacional":

Destina-se esta seção ao estudo da política militar brasileira e dos problemas da defesa nacional, em suas linhas fundamentais e de interesse coletivo. Para esse fim, ela receberá especialmente a colaboração dos militares de terra, mar e ar, e também de civis que 
se tenham especializado em problemas conexos com os problemas militares da defesa nacional ${ }^{6}$.

Essa divisão será mantida ao longo dos primeiros 18 meses de publicação. Em setembro de 1942, a linha editorial de Cultura Política é ligeiramente reformulada, passando a incluir a publicação de fotos, e as seções são redefinidas e renomeadas, recebendo os seguintes títulos:

Problemas regionais; Administração; Trabalho; Produção; Finanças; Educação; Transportes e comunicações; Política nacional; Política internacional; Política militar e defesa nacional; Povoamento; Literatura; Literatura pan-americana; Folclore; Quadros e costumes regionais; Quadros do passado brasileiro; Música; Artes plásticas; Cinema e teatro; Radio; Filologia; Biografia; Bibliografia; Textos e documentos; Inquéritos e reportagens; O Brasil no exterior.

As reflexões deste artigo estão baseadas sobretudo na "primeira etapa” da existência de Cultura Política, quando são publicados seus textos mais importantes, de caráter analítico, nos quais os temas serão tratados com maior profundidade e vagar, desenhando a pretensa ossatura do Novo Estado e definindo as instituições que lhe seriam pertinentes, orientando a condução da política dentro dos ditames estado-novistas e, portanto, de acordo com as necessidades do Brasil real ${ }^{7}$.

6 A divisão de Cultura Política nessas seções mantém-se inalterada até julho de 1942, quando é criada a seção "Cronologia biográfica e doutrinária do Presidente Getúlio Vargas", inserida como subseção em "O pensamento político do Chefe de Governo”. Essa seção tinha como objetivo enumerar todos os textos, livros e quaisquer outras manifestações culturais ou intelectuais que tivessem o Estado Novo ou Vargas como tema.

7 Dessa forma, concorda com Figueiredo (1968), que considera esse o momento mais importante de Cultura Política. Pode-se ainda salientar a similaridade da organização dos temas em Cultura Política com os temas tratados em crônicas preparadas pelo DIP, irradiadas 5.848 vezes ao longo de 1941, por meio de 68 emissoras de rádio diferentes (cf. DIP, 1941, p. 4-5). Isso indica um esforço coordenado entre os diversos setores do DIP, no sentido de uniformizar a comunicação do regime. 


\section{A democracia nas páginas de Cultura Política}

Alinhado com preocupações que nortearam o pensamento social das décadas de 1920 e 1930, Almir de Andrade alicerça sua crítica ao liberalismo nas singularidades da formação histórica do país. Nascido em 1911, no Rio de Janeiro, Andrade logo terá contato com as letras e, por meio delas, envolver-se-á com o Estado Novo. Antes mesmo de ingressar na Faculdade de Direito da Universidade do Rio de Janeiro, em 1927, debuta como autor nas páginas de periódicos colegiais, sendo a literatura seu assunto preferencial. Formado em 1931 em Ciências Jurídicas e Sociais, será colaborador do jornal A Razão, dirigido por Plínio Salgado, futuro chefe nacional da Ação Integralista Brasileira.

Nos textos de Almir de Andrade, mais uma vez a idéia de liberalismo está inegavelmente relacionada a uma noção específica de democracia. Em Força, cultura e liberdade, de 1940, o jornalista fluminense propõe uma concepção de evolução histórica baseada em parâmetros históricos e sociológicos. Nesse sentido, determinadas situações históricas conformariam os desdobramentos da vida social, sendo possível, dessa forma, conceber a sociedade movendo-se de acordo com as leis, a exemplo da natureza. A sociedade não seria conduzida pelo acaso nem estaria sujeita ao arbítrio (Oliveira apud GOMES, 1982, p. 35). Seguindo o exemplo de vários de seus contemporâneos, Andrade pensou o Estado em uma organização social de cunho liberal: "Como o liberalismo, com seus princípios liberalizantes e de alcance universal, permitira a proliferação das desigualdades e injustiças, caberia ao Estado corrigir tal situação, preservando as condições de igualdade para que cada um pudesse desenvolver suas potencialidades sem ocupar o espaço do outro (idem, p. 39)".

O Estado, nos escritos de Andrade, assume o papel de organizador máximo da sociedade, sincronizando os interesses dos diversos setores sociais com o objetivo de alcançar a harmonia social. A democracia, nesse sentido, é a obtenção desses resultados. Ao abordar uma idéia comum aos homens de letras do Brasil do início do século $\mathrm{XX}$, Andrade procura uma democracia de fins e não de meios, para utilizarmos o vocabulário característico do período. Logo no primeiro número de Cultura Política, esse é o argumento utilizado pelo autor: 
Mas a democracia é uma instituição viva e, por isso mesmo, uma instituição que evolui e que acompanha as mutações da vida. A democracia é um ideal de solidariedade humana, de respeito ao trabalho e aos frutos do trabalho, de lealdade e sinceridade na cooperação de todos os homens para o bem comum - sem distinções de privilégios, nem de raças, nem de classes, nem de fortunas (ANDRADE, 1941a, p. 5).

A democracia não seria obtida por meio dos falidos jogos liberais, mas, sim, pela aceitação de seu conteúdo valorativo. Além de ser um conceito baseado na moral, a democracia evolui, alcança os novos tempos, redefine suas atribuições, deve ser reavaliada. Uma das mais importantes reavaliações preconizadas por Andrade é justamente a distinção entre democracia e liberalismo, como aponta uma comentadora de seus escritos: "Defendendo a democracia, rejeita o liberalismo; este estaria falido. Seu sentido histórico fora antidemocrático, embora seus ideais aparentemente estivessem vinculados à democracia" (Oliveira apud GOMES, 1982, p. 39).

A democracia surge como um valor, como uma máxima para se pensar o todo social. Na visão de Andrade, ela não pode ser confundida com os jogos liberais, os quais, a pretexto de defendê-la ou torná-la possível, negaram sua existência. Essa negação advinha precisamente da incapacidade do liberalismo de realizar a democracia que prometia, o que o tornou um sistema político falido, em desacordo com as necessidades evolutivas da sociedade. Novos tempos exigiram uma nova democracia, novas idéias, com o objetivo de adequar as práticas políticas a um mundo em profunda transformação: "A democracia moderna não pode se desligar da grande crise social e econômica do mundo. De um mundo que clama por novas soluções, que nos arrasta, a passos de gigante, para o limiar de uma nova era - em que as novas formas de vida e de organização social virão substituir as antigas, que já cumpriram a sua missão" (ANDRADE, 1941a, p. 7).

As necessidades do desenrolar histórico marcam as mudanças sociais. Pela primeira vez, nas páginas de Cultura Política, o Estado Novo é lembrado (ainda que não citado) como uma urgência contingencial. Como se repetirá exaustivamente nos números subsequientes da revista, Vargas foi o grande intelecto que identificou os "novos ventos" nacionais e internacionais e reorganizou o Brasil conforme as novas contingências sociais, políticas e econômicas do momento. 
Um novo mundo descortina-se aos olhos de Andrade: um mundo em crise econômica e social. Para lidar com as novas necessidades desse mundo, a democracia surge como uma meta a ser atingida. Não a democracia pretensamente desejada pelo liberalismo, mas, sim, um conjunto de valores que organizariam a nova sociedade, que construiriam instituições políticas e sociais adequadas, ao mesmo tempo em sintonia com as especificidades do Brasil e com as urgências do mundo moderno. E, ainda, uma democracia capaz de criar um ambiente de trabalho e lei, apropriado para o desenvolvimento das capacidades de todos os indivíduos: "Sintetizando, podemos dizer que, em Almir de Andrade, a democracia é um princípio e uma meta, sua garantia é a lei, sua condição é o livre desenvolvimento da pessoa através do trabalho" (Oliveira apud GOMES, 1982, p. 40).

E é justamente com a emergência do Estado Novo que Almir de Andrade acredita estar surgindo a nova democracia no Brasil:

Mais uma vez mudamos, em novembro de 1937, o nosso sistema de Governo, procurando adaptá-lo às nossas realidades mais prementes e também àquilo que julgávamos ser as tendências mais imediatas da evolução política do mundo, na fase de transição por que passa. [...] O sistema político que adotamos nasceu das condições históricas e sociais que precipitaram a Revolução de 1930 e que se cristalizaram no atual regime (ANDRADE, 1941b, p. 6).

Além de ser a realização dos ideais de 1930, o Estado Novo estaria adaptando as instituições nacionais, a um só tempo, ao verdadeiro Brasil e ao mundo contemporâneo. A procura da alma brasileira, comum no período, será o leitmotiv de outro colaborador de Cultura Política, que também tem na democracia um de seus assuntos preferenciais: Cassiano Ricardo.

Buscando na formação histórica do Brasil os modos políticos que deveriam organizar o país, Cassiano Ricardo acaba por conceber um país cujos principais elementos constitutivos são a força, a autoridade e a tendência popular à obediência. A bandeira é o melhor exemplo dessa tendência brasileira a um tipo especial de democracia:

A democracia não podia nascer na zona do criatório nem na dos engenhos. [...] Ao passo que a bandeira nasce num meio democráti- 
co; a sua mobilidade só se explica pela pequena propriedade e pela pequena agricultura, além de povoar o país, criando-lhe a substância viva da democracia; além de corrigir os quistos étnicos vermelhos e negros, como tapuias e dos negros aquilombados nos Palmares; além de confraternizar e hierarquizar as cores num só grupo humano e social, para uma só direção (RICARDO, 1941, p. 117).

A democracia brasileira, portanto, conforma uma sociedade harmônica. Foi uma força, uma tendência que venceu os empecilhos à criação da nação, do país. Não é dissolvente como pretende ser a democracia de cunho liberal, não afeita aos traços constitutivos do caráter nacional:

De qualquer modo, entre nós, será a revivência do espírito bandeirante, e não a nostalgia do feitor transformado em culto cívico. O governo de um só, que reflete aquela sede de autoridade (nós temos sede de autoridade, dizia Poincaré) própria desta hora social, tão colorida, se obedece à simplificação dos grandes momentos humanos e coletivos - que precisam criar o responsável - da mesma forma que instituem o poder direto e o plebiscito, dispensando as representações fúteis e os intermediários anacrônicos, não será apenas "a relação entre o cesarismo e a vida no quadro das massas" senão também a salvação sumária dos povos que se refugiam no original e no originatório de sua história (idem, p. 131) ${ }^{8}$.

A autoridade é uma das marcas do espírito da bandeira, e ser afeito a ela é, indiscutivelmente, uma característica do povo brasileiro. Mescla-se, aqui, a idéia de democracia com a idéia de ordem. Mais que uma vontade ou desejo específico do autor, ela seria a correta expressão das necessidades políticas brasileiras. Democracia sem ordem seria impensável na realidade política brasileira, principalmente tendo o liberalismo como inspiração da política. A tendência a seguir uma autoridade constitui um elemento da vida nacional identificável em sua história, e a bandeira é apresentada como prova dessa assertiva: "[...] O governo forte decorre da autoridade mesma de que se revestia o condutor da bandeira para realizar as aspirações do grupo e manter-lhe a inquebrantável unidade. [...]

8 O trecho entre aspas é uma citação de $O$ Estado nacional, de Francisco Campos. 
O nosso sentimento de apego à autoridade forte nasceu daí; e não de um resíduo masoquista” (idem, p. 121).

A verdadeira democracia, a que pode auxiliar de modo apropriado na ordenação política brasileira, exige a ordem, a autoridade, e está intrinsecamente ligada a elas. $\mathrm{O}$ bandeirante teria sido o primeiro a descobrir isso, forjando, assim, a primeira ação no sentido de dotar o Brasil de um governo adequado às suas características: "O bandeirante, exercendo um poder público, que lhe é outorgado pela coroa, ou que ele próprio se atribui, cria uma restrição violentíssima à concepção de Estado de origem peninsular para fazer nascer a idéia de um governo próprio, já com raízes que buscam seiva e alimento numa nova realidade humana e social" (idem, p. 126).

Antes mesmo da emergência de governos fortes na Europa, durante o surto conservador que sucede o fim da I Guerra Mundial, o bandeirante já havia concebido um governo que possui na ordem e na autoridade seu traço distintivo: "Antes de haver 'fascismo' europeu ou qualquer outro 'ismo' já a bandeira havia revelado, por instinto, as linhas estruturais que hoje condicionam o Estado moderno: comando seguro e fraterna solidariedade dos indivíduos obedientes à firme unidade de comando" (idem, p.132).

A democracia brasileira deveria ser, portanto, um reencontro das instituições políticas com a história nacional. Se o bandeirante é um elemento constitutivo dessa história e seus hábitos condicionaram a formação da mentalidade do brasileiro, nada mais justo que procurar nessa instituição os princípios norteadores básicos das práticas políticas a serem implementadas no Brasil.

E como orientar o país na procura de uma democracia adequada? Como estabelecer as práticas políticas exigidas para suprir as deficiências causadas pelo liberalismo - na perspectiva dos ideólogos do Estado Novo, um conceito vago e amplo, muitas vezes mesclado ou confundido com democracia ou "democratismo"? As páginas de Cultura Política serão marcadas por essa procura. Azevedo Amaral será um dos mais tenazes escrutinadores desse conjunto de novas normas. Partindo de um diagnóstico preciso da realidade brasileira, desde sua formação até a contemporaneidade, Amaral apresentará propostas claras para o "novo" Brasil. Seguindo a lógica de Andrade, também esse autor utiliza a formação histórica do 
Brasil para compreender seu presente. Em primeiro lugar, existe um republicanismo "autóctone" no Brasil:

O nosso republicanismo colonial emergira espontaneamente das condições econômicas e sociais do meio brasileiro. Tinha assim as características inconfundíveis de uma criação autêntica das forças plasmadas da nacionalidade e era, portanto, uma corrente mais instintiva que ideológica, integrada e profundamente enraizada na realidade nacional (AMARAL, 1941b, p. 156).

Existe, portanto, um conjunto de instituições políticas brasileiras. Só resta seguir as indicações "naturais" e elaborar um projeto político apropriado. E, ainda mais importante, deve-se evitar implementar práticas "alienígenas", pois estas seriam perniciosas para o Brasil. Uma das vãs tentativas de fazer isso foi um lamentável erro, que deveria ser corrigido: "O regime democrático foi instituído entre nós sem que o povo tivesse compartilhado ou pelo menos se interessado pela grande metamorfose que se operava" (idem, p.163).

Com um republicanismo original, fruto das condições singulares da formação social e histórica brasileira, caberia aos grandes homens do país elaborar um conjunto de novas instituições que recolocasse o Brasil no "caminho correto de sua evolução"; caminho que havia se perdido em um emaranhado de idéias tresloucadas que pretendeu implantar no país práticas exóticas, em desacordo com o "caráter nacional”. Assim, o Estado Novo - Vargas em especial - é mais que uma nova ordem política, é o reencontro do Brasil com seu verdadeiro destino:

A influência do Chefe Nacional despertou no povo força de ação cívica com as quais ele pode plasmar instituições novas, chegando na lógica desse processo evolutivo ao coroamento da obra renovadora com a Constituição de 10 de novembro de 1937. Dentro das configurações do Estado nacional, a política republicana seguirá o curso da sua marcha progressiva sem sobressaltos e sem afastarse das linhas traçadas pelas realidades históricas e atuais, em uma adaptação evolutiva às situações e aos problemas novos que forem surgindo (idem, p.171-172).

O Estado Novo é concebido, então, como o momento mais importante da história republicana brasileira. Uma inflexão na con- 
dução dos processos evolutivos da nacionalidade. Se o diagnóstico estava elaborado, agora restava estabelecer os padrões dessa nova etapa da história brasileira. As páginas de Cultura Política esboçarão esses novos parâmetros, seguindo as mediações necessárias com as contingências momentâneas da vida política e econômica tanto nacional como internacional.

\section{O Estado em Cultura Política}

Assim como um ideário específico da democracia é cuidadosamente composto nas páginas de Cultura Política, os ideólogos do Estado Novo não deixaram de expressar suas noções sobre o funcionamento do Estado brasileiro. Os argumentos desses articulistas convergem para uma visão de Estado específica, mas organizada nos termos do mesmo vocabulário político que vem sendo analisado neste artigo.

Profundamente conectado à idéia de organização da sociedade, o Estado foi tematizado em várias páginas de Cultura Política. $E$, entre as carências do Brasil, estava justamente a inexistência de um corpo de idéias caracteristicamente brasileiras. No hiato entre o Brasil real e o Brasil legal deu-se a desagregação da nação:

Pois o que se passa na vida dos indivíduos repete-se na vida dos povos. Há nações que agem em função de princípios e visam objetivos correlatos: Nietzsche e Spengler formaram a consciência alemã e ditaram um rumo ao seu povo. Tais nações se organizam em Estados que sabem o que querem e para onde vão. Quanto a nós, entretanto, no Brasil liberal, jamais a nação se expressou em uma individualidade que, colhendo exemplos e inspiração na tradição e na realidade, fosse capaz de criar uma doutrina própria, pela qual se pudesse chegar a determinado fim (FIGUEIREDO, 1984a, p. 49).

Essa doutrina passaria, necessariamente, pela elaboração de um Estado em conformidade com a índole nacional. O liberalismo objetivou construir esse Estado, mas, como resultado, o Brasil entrou em uma crise generalizada:

O homem, no liberalismo, desprende-se das coisas, e estas, sem o contato humano, abandonadas a si próprias, fenecem, por artifi- 
ciais, irreais, a-humanas. Sem se ligarem e interpenetrarem numa rede de relações profundas, homens e coisas - não se organizando estas, longe de servirem ao homem, com ele colidem - e o homem, não encontrando nelas meios de expressão e de expansão, topa nelas obstáculos ao seu desenvolvimento. Foi o que sucedeu no antigo regime, quando nem as coisas se organizaram, nem o homem se firmou (idem, p. 51).

Uma crise moral, portanto, abateu-se sobre o homem brasileiro, no afã liberal de organizar a sociedade de uma forma inadequada. Ainda mais importante, aos olhos de Paulo Augusto de Figueiredo, foi a incapacidade do liberalismo de gerar um Estado adequado. $E$, exatamente da relação entre os indivíduos e o Estado, surge a pedra de toque do sucesso social: "A boa política organiza o Estado tendo em vista realizar, por ele, os fins dos homens, como indivíduos e como coletividade. A política liberal, porém, jamais considerou o homem e o Estado em sua justa posição. Dessa incompreensão política nasceu a dissociação, o antagonismo entre o Estado e o indivíduo, e daí o caos" (idem, p. 53).

Uma forma irrefutável de demonstrar as mazelas e a incompreensão política geradas pelo Estado liberal é a instituição do voto universal como mecanismo de participação política. Tema caro ao debate político brasileiro das décadas iniciais do século XX, o sufrágio universal foi constantemente apontado como exemplo dos desmandos do regime liberal. Assim, foi sugestivamente acusado de ser gerador de desigualdades, instrumento de embuste público, fator de desagregação social ou, ainda, o estopim de guerras facciosas. Pois aqui, ao tratar do Estado, novamente o voto é visto como uma forma de impedimento à maioridade política do país:

Daí, entre outras anomalias, o sufrágio universal - aberração política verdadeiramente catastrófica entre nós. Povo inculto, pobre, doente, o povo brasileiro não era livre o bastante, nem bastante educado, para com ele se tentar a experiência. As consequiências do sufrágio universal ainda estão visíveis: a desagregação do caráter do povo (com a venda do voto), o seu apassivamento (a que se apelida "carneirismo"), o advento deste tipo funesto, chamado "coronel" (geralmente bronco e mau) de quem dependia a vida municipal (idem, p. 54). 
As práticas políticas brasileiras seriam, portanto, o simples reflexo dos mecanismos escolhidos para organizá-las. Em um país de miseráveis e incultos, o sufrágio nada mais fez que exacerbar vícios, corromper instituições e fortalecer uma idéia de Estado dissociada dos interesses da maioria da população. O sistema de representação popular calcado no voto transformou-se, portanto, em uma farsa:

Daí o sistema representativo, que, entre nós, na era republicana, não passou de pretexto para exibicionismos ridículos e negociatas escandalosas - representando as câmaras altas, espécie de circo onde se digladiavam os partidos em torno de princípios inócuos ou de apetites pessoais, e as baixas, as municipais, espécie de currais de bois mansos (ibidem).

Desnecessário fazer aqui um paralelo entre a assertiva acima e as opiniões expressas por Azevedo Amaral, por exemplo. Interessante de notar-se é o completo desprezo pelo voto. Nesse ponto, tem-se uma especificidade da fala de Figueiredo, na qual as atribulações causadas pelo voto resultam também em um Estado mal organizado:

Por isso, não tínhamos um Estado que não seria possível organizar com elementos importados, porque o Estado é coisa natural, nasce com tal ou qual fisionomia, conforme o meio em que se forma. $\mathrm{O}$ território aí estava, imenso, rico; o povo aí estava, com as suas tradições, a sua história, as suas necessidades, os seus anelos. Só não tínhamos um princípio de vida pública, uma política, um governo - a terceira e mais importante, talvez, das componentes de um Estado (idem, p. 55).

Obviamente, o regime ao qual o autor faz referência é o Estado Novo, que emerge de sua lógica como o regime (ou governo) que, pela primeira vez, teve a capacidade de aglutinar as forças políticas da nação em torno de um Estado adequado ao verdadeiro caráter brasileiro. Ao referir-se ao Estado Novo, fica patente a opinião de Figueiredo:

E aí está o primeiro traço verdadeiramente original do novo Estado. É que o Estado deve ser um meio, e não um fim. Os homens se organizam em busca da felicidade. E o Estado é a condição de realização desse objetivo, pois que amplia as forças dos indivíduos, 
a fim de que estes consigam, em conjunto, o que, por si, lhes seria impossível obter. Por isso os fins do Estado se confundem com os fins do indivíduo, ou melhor, o Estado é um simples meio de que se aproveitam os homens para cumprir seu destino (idem, p. 58).

Dos escombros de um Estado transformado em palco de circo no velho regime, assiste-se, portanto, ao surgimento de um Estado que é a união dos interesses dos indivíduos. O Estado Novo emerge como o grande aglutinador das forças políticas nacionais, centralizando a decisão política e conformando uma ordem que possui a democracia como um valor a ser obtido, independentemente dos meios utilizados para obter-se a ordem pretensamente democrática e adequada aos interesses gerais dos indivíduos a ela subordinados. A sugestão da urgência da criação de um "poder central" no Brasil é um elemento recorrente no pensamento social brasileiro, uma perspectiva exposta de maneira lapidar, por exemplo, por Oliveira Vianna, quando o autor fluminense manifesta sua simpatia pela centralização política do Império do Brasil. No trecho abaixo, Figueiredo ressalta justamente a centralização política como um ponto da nova organização do país:

$\mathrm{Na}$ ordem política, atingimos o regime centralizador, único compatível com a nossa realidade geográfica e étnica. O fortalecimento do poder central deu em resultado uma atuação em torno de um ponto único, desaparecendo os privilégios regionais com todas as suas más consequiências. Não se distinguindo mais entre interesses dos Estados, que estão todos incluídos no interesse do Brasil, os brasileiros perderam a sua naturalidade, em benefício de sua nacionalidade. As forças dispersas e dispersivas se uniram e se disciplinaram, metamorfoseando-se numa força única e poderosa: a força nacional (idem, p. 65).

Pois esse fortalecimento do Estado central, em comparação ao constante amesquinhamento dos interesses regionais reinantes no antigo regime, é um "dado natural", uma necessidade de todo grupo humano. Nesse argumento, o Estado surge como o ente político definitivo, incontornável e indispensável para a organização política da sociedade. Relacionando imperativos naturais, ordem legal e sociedade, Figueiredo assinala a posição do Estado na ordem social: 
O direito é anterior e superior ao Estado. A sua condição mesma de vida. Onde há agrupamentos humanos há interesses recíprocos, há conflitos, e daí a necessidade de uma entidade que organize a vida social dos homens, em benefício de todos e de cada um. Quem regula essas relações é o direito: quem organiza esses agrupamentos é o Estado. Este surge, assim, como um dado natural e imperioso da existência social dos homens (FIGUEIREDO, 1984b, p. 71).

O Estado é a política, portanto. Não como regulador de conflitos, mas como instrumento de abolição do conflito social. Uma organização que agrupa em torno de si todos os indivíduos de uma sociedade. Mas, além de seu caráter organizativo, o Estado, como foi mostrado nas páginas de Cultura Política, é a única opção válida para a vida política da nação. Não existe política fora do Estado. Mesmo que Paulo Augusto de Figueiredo esteja constantemente interessado em marcar a diferença entre o Estado Novo e um Estado de viés totalitário, como se depreende da seguinte passagem:

No Estado liberal há partidos, e, tendo cada grupo uma consciência própria e fins próprios, segue-se que o Estado não tem fins, e, por conseguinte, não pode ter um caráter, não pode ser típico, nacional. No Estado comunista as classes estão acima dos homens. O Estado totalitário está fora e acima dos indivíduos, não tem, portanto, conteúdo humano, sendo um Estado que existe pelo Estado e para o Estado (FIGUEIREDO, 1984a, p. 59).

Na Teoria do Estado proposta por Figueiredo, temos, portanto, em um só movimento, os distintos Estados possíveis, ou seja, os existentes naquele momento: o liberal, o comunista e o totalitário. Cada um deles é, por cada uma de suas características, inadaptável ao Brasil. O Estado liberal imobiliza a condução política da sociedade, perdido em um sem-número de interesses fragmentados e fragmentadores. No Estado comunista, as classes sociais enterram os indivíduos. Ao passo que o Estado totalitário transforma o próprio Estado em razão política, em um fim a ser obtido pela organização social. Para combater os males de cada um desses Estados inadequados, foi elaborado e implementado no Brasil um Estado que está em sintonia com os interesses nacionais: não se esquece do indivíduo, mas impede que interesses individuais 
organizem a ordem social; não dá vazão aos conflitos entre capital e trabalho, mas organiza essa relação, negando o conflito que lhe é característico; acredita no Estado, mas não o transforma em razão de ser da política. Um Estado novo, portanto:

O Estado brasileiro firmou-se como um Estado síntese, integração superior do Estado liberal (tese) e do Estado totalitário (antítese). Não opera o Estado Novo num clima de pura abstração; mas também não atua somente no plano das "realidades aparentes". A política getuliana persegue o ponto neutro entre os extremos. Tenta, o chefe nacional, a apreensão total da nossa realidade, física e anímica - da nossa terra, portanto, e da nossa gente, povo -, mas este como povo humano e como povo nacional. Toda a sua atividade tem em mira equilibrar o Estado, situando-o no zero da escala política, onde os extremos se tocam e se fundem e se completam e se corrigem (FIGUEIREDO, 1984b, p. 73).

No afã de construir uma nova prática política, que conecte as instituições nacionais aos seus modos políticos, é mister, aos olhos de Figueiredo, uma transformação dos costumes sociais brasileiros. Quase paralelamente à idéia revolucionária proposta por Plínio Salgado, que sugeria uma transformação interior como elemento inicial de uma revolução social, Figueiredo credita ao Estado Novo o mérito de ter-se empenhado na construção de um novo homem:

O Estado brasileiro, como se vê, visa muito além da simples armação objetiva da nossa pátria. A organização das várias instituições, de ordem econômica, social, jurídica, política, constitui apenas um método de construção de algo que supera todas as entidades - o homem. Mas o homem ampliado, o homem em sua expressão coletiva - o povo. O que se pretende, com as atuais realizações objetivas, é o estabelecimento de um meio próprio à efetivação de tal mister. Em última análise, o que a nova política busca é dar ao brasileiro, como povo, uma razão nacional de viver (idem, p. 77).

Além de organizar a sociedade brasileira em bases adequadas, por meio de um Estado com a vocação necessária para tal fim, o Estado Novo acaba, na ótica de Figueiredo, por dar uma nova orientação à vida nacional. Trata-se não apenas de política ou economia, mas de um regime que dotou sua população de uma nova 
ética, de um novo conjunto de relações, uma vez que "o Estado Novo [...] já nos deu uma razão nacional de ser. Sabemos, já, por que existimos" (ibidem). Assim, além de proporcionar ao brasileiro um nova organização política, o Estado Novo deu-lhe uma razão para existir. O Estado Novo não é apenas mais um regime, um Estado, uma opção política (ainda que inevitável); o regime de Vargas reelaborou o país, criando um fim nacional a ser alcançado: "Com uma razão nacional de existir e um modo nacional de ser, tem o Estado brasileiro um fim nacional a atingir. Completa-se, dessarte, a nossa fisionomia. Ganhamos personalidade. Temos consciência do nosso destino. Por isso, temos, agora, os nossos métodos e visamos fins determinados" (idem, p. 79).

Construir um Brasil uno, ciente de seu destino de nação, com um objetivo único e indiscutível: a construção de uma nação. Uma comunidade política organizada no entorno de uma máquina estatal que abarca praticamente todas as dimensões da existência social dos indivíduos. Nas palavras de Paulo Augusto de Figueiredo: "Fazer do nosso homem, mas como homem brasileiro, um tipo humano superior - e fazer da nossa Pátria, mas como célula política universal, uma grande pátria - eis a finalidade do Estado brasileiro" (idem, p. 80).

Um homem que seria criado em um novo ambiente, marcado pela centralização inaugurada em 1937. Essa é a principal idéia defendida em "Aspectos de nossa organização política", artigo publicado por Inácio José Veríssimo em Cultura Política. Esse autor, então Tenente-Coronel do Estado Maior da $4^{\mathrm{a}}$ Região Militar, aborda os principais elementos da organização política brasileira. Propondo uma argumentação de cunho histórico, Veríssimo elege a centralização empreendida em 1937 como o grande mote de seu artigo. Nada mais justo, pois, segundo seu escrito, a descentralização teria sido o grande mal do Brasil republicano: "[...] Paira sobre nós uma necessidade fatal: a criação de um governo central forte, capaz de representar a Nação e não ser apenas o representante de um arranjo político entre partidos regionais. $\mathrm{E}$ assim a democracia involui entre nós porque acabou nociva à própria Pátria” (VERÍSSIMO, 1941, p. 33). 
Um Estado que perdeu suas prerrogativas e, com isso, criou embaraços para a democracia. Mas, finalmente, em 1937, esse estado de coisas é alterado: "Em 1937 o Brasil encontrou, afinal, a fórmula única de ser governado; a fórmula que permite - pela descentralização administrativa atender a geografia - e pela unidade política emanada da fortaleza do centro, refundir o Brasil numa Nação única, numa vontade poderosa, numa expressão política digna de sua extensão física" (idem, p. 43).

Essa fortaleza construída no centro do poder nacional, nas palavras de Veríssimo, foi escrutinada nas páginas de Cultura Política. Compreendido como obra renovadora, fruto da vontade de homens empenhados na construção de um novo Brasil, o Estado Novo foi inevitável do ponto de vista histórico. Uma fatalidade, um imperativo. Uma nova organização para um país convulsionado por idéias e práticas políticas inadequadas à sua realidade. Essa nova organização social e política foi montada fazendo-se o elogio a uma democracia que prescindia da participação ativa dos indivíduos, aglutinados por um Estado centralizado, centralizador e autoritário.

Recebido em 10.1.2008

Aprovado em 26.03.2008

\section{Referências bibliográficas}

ABREU, A. A. (coord.). Dicionário histórico-biográfico do Brasil pós-30. 2a ed. Rio de Janeiro: Fundação Getúlio Vargas, 2001.

AMARAL, A. Evolução da política republicana. Cultura Política, Rio de Janeiro, ano I, n. 3, 1941.

ANDRADE, A. (dir.). Cultura Política, Rio de Janeiro, 1941-1944.

. A evolução política e social do Brasil. Cultura Política, Rio de Janeiro, ano I, n. 1, 1941a.

. A soberania internacional do Brasil. Cultura Política, Rio de Janeiro, ano I, n. 3, 1941b.

- Almir de Andrade I. Entrevista concedida em 10.jan.1981 ao Programa de História Oral do Centro de Pesquisa e 
Documentação de História Contemporânea do Brasil. Rio de Janeiro: Fundação Getúlio Vargas, 1986a.

. Almir de Andrade II. Entrevista concedida em 27.set.1984 ao Programa de História Oral do Centro de Pesquisa e Documentação de História Contemporânea do Brasil. Rio de Janeiro: Fundação Getúlio Vargas, 1986a.

ARAÚJO, R. B. Totalitarismo e revolução: o integralismo de Plínio Salgado. Rio de Janeiro: J. Zahar, 1987.

BEVIR, M. The Logic of the History of Ideas. Cambridge: Cambridge University, 1999.

CODATO, A. Os autores e suas idéias: um estudo sobre a elite intelectual e o discurso político do Estado Novo. Estudos Históricos, Rio de Janeiro, n. 32, p. 145-164, 2003.

DIP. Relatório anual. Rio de Janeiro: Departamento de Imprensa e Propaganda, 1941.

DUTRA, E. $\mathrm{O}$ ardil totalitário: imaginário político no Brasil dos anos 30. Rio de Janeiro: UFRJ, 1997.

FIGUEIREDO, M. Cultura Política: revista teórica do Estado Novo. Dados, Rio de Janeiro, n. 4, 1968.

FIGUEIREDO, P. A. O Estado brasileiro e o sentido do nacionalismo. In:

Senado Federal, 1984b. Aspectos ideológicos do Estado Novo. Brasília:

FIGUEIREDO, P. A. O Estado nacional como expressão das necessidades brasileiras. In: Estado Novo. Brasília: Senado Federal, 1984a. . Aspectos ideológicos do

GOMES, A. M. C.; OLIVEIRA, L. L. \& VELLOSO, M. P. Estado Novo: ideologia e poder. Rio de Janeiro: Zahar, 1982.

LENHARO, A. A sacralização da política. Campinas: Papirus, 1986.

MEDEIROS, J. Ideologia autoritária no Brasil, 1930-1945. Rio de Janeiro: Fundação Getúlio Vargas, 1978.

RICARDO, C. O Estado Novo e o seu sentido bandeirante. Cultura Política, Rio de Janeiro, ano I, n. 1, 1941. 
SILVA, R. A ideologia do Estado autoritário no Brasil. Chapecó: Argos, 2004.

VARGAS, G. Diários. São Paulo: Siciliano, 1995.

VELLOSO, M. P. Cultura e poder político: uma configuração do campo intelectual. In: GOMES, A. M. C.; OLIVEIRA, L. L. \& VELLOSO, M. P. (orgs.). Estado Novo: ideologia e poder. Rio de Janeiro: Zahar, 1982. VERÍSSIMO, I. J. Aspectos de nossa organização política. Cultura Política, Rio de Janeiro, ano I, n. 4, 1941. 
